\title{
Synthesis of Fused and Linked Benzofurans from 2-Alkynylphenol Derivatives through Rhodium(I)-catalyzed Domino-type Addition Reactions
}

\author{
Takanori Matsuda*a, Shinya Abe ${ }^{a}$, Hirotaka Ito ${ }^{a}$, Tomoya Tsuboi ${ }^{\text {, }}$ Haruki Kirikae ${ }^{\mathrm{a}}$, and Masahiro \\ Murakami*b \\ With the best tribute to the memory of my mentor, late Professor Teruaki Mukaiyama who passed \\ away on November 17, 2018 at the age of 91.
}

\begin{abstract}
A rhodium(I)-catalyzed domino-type sequential 5-endo/5-exo cyclization reaction of [(2-acylphenyl) ethynyl]phenols produces indene/benzofuran-fused alcohols. A moderate asymmetric induction is observed when chiral diphosphine ligands are used for rhodium. Indene/indole-fused compounds are synthesized by a similar reaction of [(2-acetylphenyl)ethynyl]anilines. The domino-type 5-endo/5-exo cyclization reaction is extended to substrates having two phenolic hydroxy groups. A linearly-fused array of five- and six-membered rings is constructed. Fused and linked benzofurans possessing 2-cyanoethyl side chains are also synthesized through sequential formation of $\mathrm{C}-\mathrm{O}$ and $\mathrm{C}-\mathrm{C}$ bonds.
\end{abstract}

Keywords: Asymmetric reaction · Benzofuran · Cyclization · Domino reaction $\cdot$ Rhodium

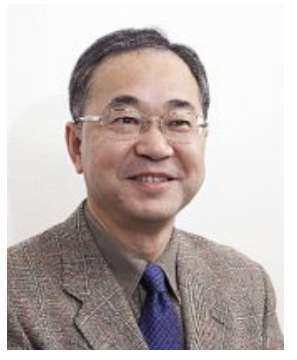

\section{Masahiro}

Murakami

is currently a

Chemistry Professor at Kyoto University. He grew up in a rice farmer's family in Toyama, Japan and then trained at the University of Tokyo, receiving his DSc in 1984 under the supervision of Prof. Teruaki Mukaiyama. He started his career with an assistant position to Prof. Mukaiyama at the University of Tokyo (1984-1987). He moved to Kyoto University taking an assistant position to Professor Yoshihiko Ito in 1987, and was promoted to Associate Professor in 1993. In the meantime, he took leave to spend ten months from May 1991 till March 1992 at the ETH Zürich as a post-doctoral fellow with Prof. Albert Eschenmoser. He was appointed to Professor in 2002 at Kyoto University. His research interests focus on the development of new and interesting organic transformations. The utilization

${ }^{\star}$ Correspondence: Prof. Dr. M. Murakami ${ }^{b}$

Dr. T. Matsuda

E-mail: murakami@sbchem.kyoto-u.ac.jp

mtd@rs.tus.ac.jp

aDepartment of Applied Chemistry

Tokyo University of Science

1-3 Kagurazaka, Shinjuku-ku, Tokyo 162-8601, Japan

bepartment of Synthetic Chemistry and Biological

Chemistry

Kyoto University

Katsura, Kyoto 615-8510, Japan of photo-energy for organic synthesis is currently the major research interest in his group.

\section{Introduction}

Benzo $[b]$ furan is a privileged structural motif prevalently found in a variety of natural products and biologically active compounds. ${ }^{[1]}$ Benzofuran derivatives have also received considerable attention as organic electronic materials in recent years. ${ }^{[2]}$ 2-Alkynylphenols are readily accessible compounds that are suitable synthetic precursors of benzofurans. They readily undergo, upon treatment with an appropriate promoter, a 5-endo cyclization reaction to construct benzofuran skeletons in an expeditious and atom-economical manner. There have been a number of promoters reported to effect the 5-endo cyclization reaction. ${ }^{[3,4]}$ Among them, the cyclization reaction catalyzed by a hydroxorhodium(I) complex, developed by Lautens, ${ }^{[4]}$ is particularly attractive since (benzofuran3-yl)-rhodium(I) species arising from the cyclization are relatively stable but active enough to further add to electron-deficient alkenes such as acrylonitrile, furnishing 2,3-disubstituted benzofurans in one-pot reactions. The domino-type addition reaction has a mechanistic distinction that the intermediate organorhodium(I) species is generated from a non-organometallic compound dispensing with pre-preparation of precursory organometallic compounds (Scheme 1). ${ }^{[5]}$

The reaction merited further investigation, targeting fused and linked compounds containing benzofuran cores, which are of much interest from the viewpoint of or-
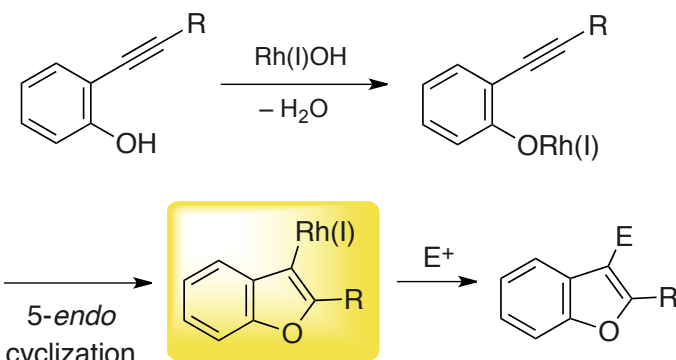

benzofuran-3-ylrhodium(I)
Scheme 1.

Generation and reaction of (benzofuran-3-yl)rhodium(I) species 
Scheme 2 .

Rhodium(I)-catalyzed domino-type

5-endo/5-exo cyclization of $\mathbf{1 a}$

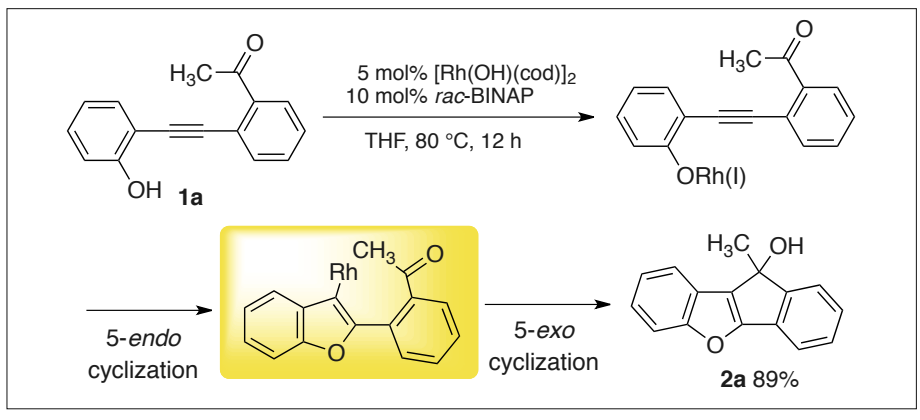

Scheme 3.

Rhodium(I)-catalyzed domino-type 5-endo/5-exo cyclization of $1^{\text {a }}$. ${ }^{\text {Reaction }}$ conditions: substrate 1 (0.10-0.37 mmol), $[\mathrm{Rh}(\mathrm{OH})(\mathrm{cod})]_{2}$ BINAP (10 mol\%), $\operatorname{THF}(0.1 \mathrm{M}), 80^{\circ} \mathrm{C}$, $12 \mathrm{~h}$. 'bsolated yield. (10 mol\% in Rh), rac-

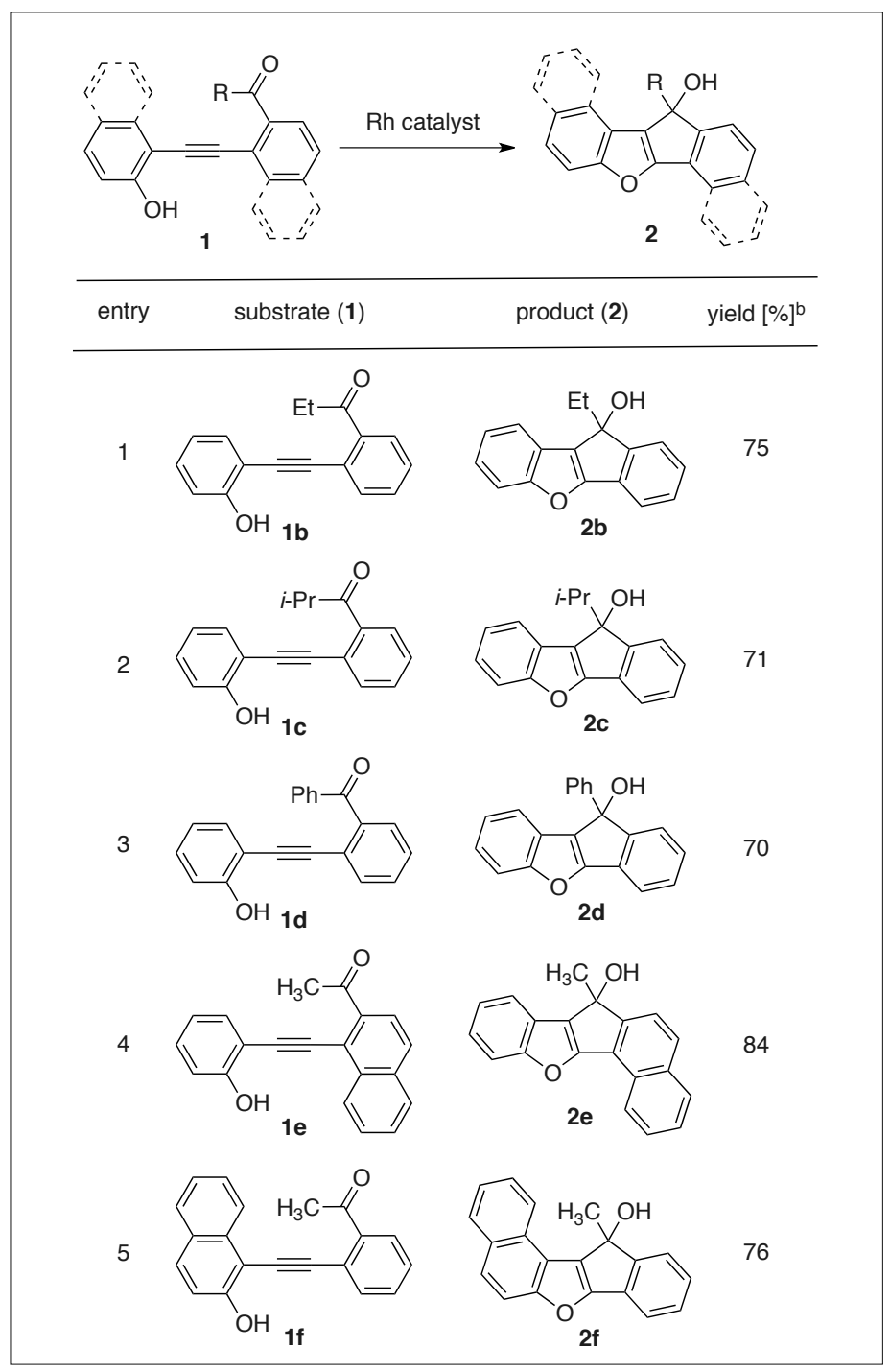

Table 1. Asymmetric cyclization of $\mathbf{1}^{\mathrm{a}}$

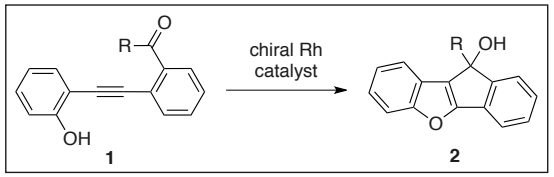

\begin{tabular}{|c|c|c|c|c|c|}
\hline entry & $1(\mathrm{R})$ & diphosphine ligand & product & yield $[\%]^{\mathrm{b}}$ & ee $[\%]^{c}$ \\
\hline 1 & $1 \mathbf{a}(\mathrm{Me})$ & $(R)$-BINAP & $2 a$ & 94 & 51 \\
\hline 2 & $1 \mathrm{a}$ & $(R)$-MeO-BIPHEP & $2 a$ & 80 & 79 \\
\hline 3 & $1 \mathbf{a}$ & (R)-C3-TunePhos & $2 a$ & 82 & 84 \\
\hline 4 & $1 \mathbf{a}$ & $(R)$-SEGPHOS & $2 a$ & $84^{\mathrm{d}}$ & $88^{\mathrm{d}}$ \\
\hline 5 & $\mathbf{1 b}(\mathrm{Et})$ & ( $R$ )-SEGPHOS & $2 b$ & $51^{\mathrm{d}}$ & $85^{\mathrm{d}}$ \\
\hline 6 & 1c $(i-\operatorname{Pr})$ & (R)-SEGPHOS & $2 c$ & $38^{\mathrm{d}}$ & $83^{\mathrm{d}}$ \\
\hline 7 & 1d $(\mathrm{Ph})$ & (R)-SEGPHOS & 2d & $53^{\mathrm{d}}$ & $86^{\mathrm{d}}$ \\
\hline
\end{tabular}

${ }^{a}$ Reaction conditions: substrate $4(0.050 \mathrm{mmol}),[\mathrm{Rh}(\mathrm{OH})(\mathrm{cod})]_{2}$ (10 mol\% in Rh), chiral diphosphine ligand $(13 \mathrm{~mol} \%)$, THF $(0.03 \mathrm{M}), 80^{\circ} \mathrm{C}, 12 \mathrm{~h}$. ${ }^{\mathrm{b}}$ Isolated yield. ${ }^{\circ}$ Determined by chiral GC (Rt- $\beta$ DEXm) or HPLC (CHIRALCEL OJ-H). ${ }^{d}$ Average of two runs. ganic electronics and nanotechnology. ${ }^{[1,2]}$ Herein, we report the results of our study on the synthesis of fused and linked benzofurans on the basis of the rhodium-catalyzed domino-type cyclization protocol.

\section{Results and Discussion}

2-[(2-Acetylphenyl)ethynyl]phenol (1a) was designed to synthesize indene/ benzofuran-fused alcohol $\mathbf{2 a}$ through domino-type sequential 5-endo/5-exo cyclization. An electrophilic acetyl group is placed on an alkynylphenol backbone in a way that an intermediate (benzofuran-3-yl) rhodium(I) species further undergoes the second cyclization onto the acetyl group in a 5-exo mode, attaching a fused indene skeleton. It was synthesized through the Sonogashira coupling reaction of 1 -iodo2-(methoxymethoxy)benzene with 2-ethynylphenyl methyl ketone and the following deprotection of the methoxymethoxy group under acidic conditions. When 1a was treated with a catalytic amount of a rhodium complex prepared in situ from $[\mathrm{Rh}(\mathrm{OH})(\mathrm{cod})]_{2}$ and rac-BINAP, indenobenzofuranol $\mathbf{2 a}$ was obtained in $89 \%$ isolated yield (Scheme 2). Initially, a rhodium(I) alkoxide is generated from 1a by deprotonation of the phenolic hydroxy group with the hydroxorhodium(I) complex. The first cyclization takes place in a 5-endo mode. ${ }^{[6]}$ The resulting (benzofuran3 -yl)rhodium(I) species then undergoes the second cyclization onto the pendent acetyl group in a 5-exo mode to afford 2a. ${ }^{[7]}$ The resulting rhodium(I) alkoxide acts as a base to release the alcohol $\mathbf{2 a}$, promoting the next catalytic cycle.

Other 2-[(2-acylphenyl)ethynyl] phenols 1b, 1c, 1e, and 1f were prepared in an analogous manner to 1a. 2-[(2-Benzoylphenyl)ethynyl]phenol (1d) was prepared through the Sonogashira coupling reaction of 2-iodobenzophenone with 1-ethynyl-2-(methoxymethoxy)benzene and the following deprotection. They successfully participated in the dominotype 5-endo/5-exo cyclization reaction to afford indene/benzofuran-fused alcohols 2b-f in good yield (Scheme 3). ${ }^{[8]}$

Induction of enantioselectivity in the second 5-exo cyclization process producing 2a was investigated using representative axially chiral biaryl diphosphine ligands for rhodium (Table 1). An enantioselectivity was modest when the most typical $(R)$ BINAP was tried (entry 1). Among other chiral ligands examined, $(R)$-SEGPHOS gave the best result in terms of both chemical yield and enantioselectivity (entries 2-4). (R)-SEGPHOS induced good enantioselectivities around $85 \%$ ee also with other substrates 1b-d, although chemical yields were moderate (entries 5-7). ${ }^{[9]}$ 
Previous work by Lautens suggested that it would be possible to extend the domino-type 5-endo/5-exo cyclization protocol for the synthesis of indene/benzofuran-fused alcohols to the synthesis of indene/indole-fused alcohols by replacing the hydroxy group with a sulfonated amino group. 2-[(Acetylphenyl)ethynyl]anilines $\mathbf{3 a}$ and $\mathbf{3 b}$ were prepared from 2-iodoacetophenone and 2-ethynylanilines by the Sonogashira coupling reaction followed by deprotection, and subjected to the identical reaction conditions. They successfully underwent an analogous domino-type 5-endo/5-exo cyclization reaction to afford indene/indole-fused alcohols $\mathbf{4 a}$ and $\mathbf{4 b}$ via sequential formation of $\mathrm{C}-\mathrm{N}$ and $\mathrm{C}-\mathrm{C}$ bonds (Scheme 4). ${ }^{[10,11]}$

We were intrigued also by the substrates bearing two phenolic hydroxy groups, each of which would trigger the 5-endo cyclization. It constructs more conjugated benzofuran structures, which would be more promising as the material for organic electronics and nanotechnology. When the hydroquinone derivative $\mathbf{5}$ was used, the domino-type 5-endo/5-exo cyclization occurred on both sides to form a linearly-fused array of five- and sixmembered rings in an expeditious manner, affording 6 in $66 \%$ yield (Scheme 5). ${ }^{[12]}$

Another hydroquinone derivative, 2,5-bis(phenylethynyl)hydroquinone (7a), ${ }^{[2 \mathrm{~d}]}$ was reacted with an excess amount of acrylonitrile (8) in the presence of a rhodium(I) catalyst. Each of the arising (benzofuran-3-yl)rhodium(I) species underwent intermolecular conjugate addition to acrylonitrile (8), introducing two 2-cyanoethyl side chains on the fused tricyclic aromatic core to afford 9a (Scheme 6). ${ }^{[4]}$

An analogous intermolecular reaction with acrylonitrile (8) was carried out using 1,4-bis[(2-hydroxyphenyl)ethynyl] benzene (7b). 1,4-Di(benzofuran-2-yl) benzene 9b was produced in 64\% yield (Scheme 7).[13] Similarly, the reaction of the corresponding 1,3-disubstituted (metadisubstituted) derivative $\mathbf{7 c}$ with $\mathbf{8}$ afforded 1,3-di(benzofuran-2-yl)benzene 9c in 63\% yield (Scheme 8).

\section{Conclusion}

In summary, a rhodium(I)-catalyzed cyclization reaction was studied using [(2-acylphenyl)ethynyl]phenols and similar aniline derivatives. Domino-type sequential 5-endo/5-exo cyclization took place to produce indene/benzofuran-fused and indene/ indole-fused alcohols, respectively. The domino-type reaction was extended to the substrates having two phenolic hydroxy groups. A linearly-fused array of five- and six-membered rings is constructed. Fused and linked benzofurans possessing 2-cya-

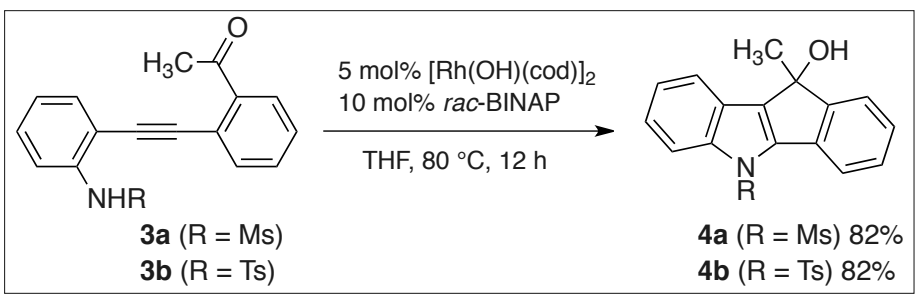

Scheme 4. Dominotype cyclization of $\mathbf{3}$.

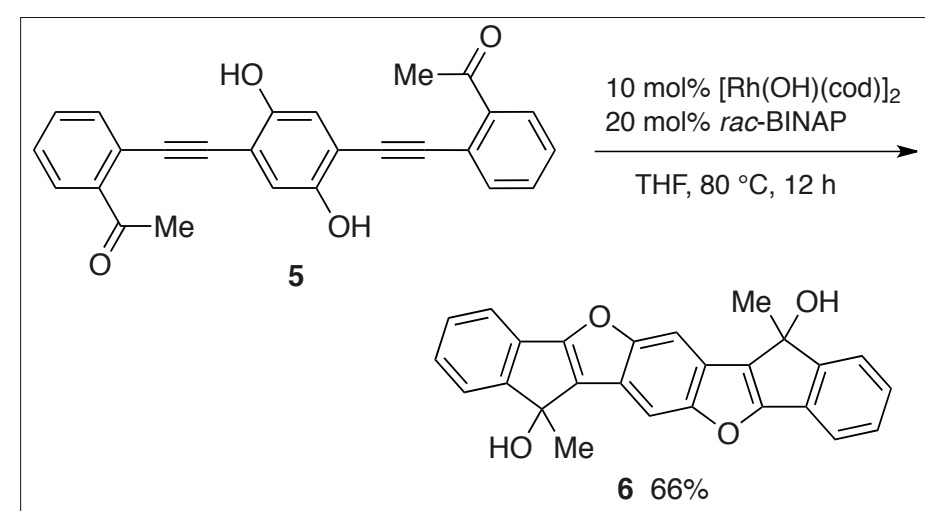

Scheme 5. Synthesis of heptacyclic product 6.

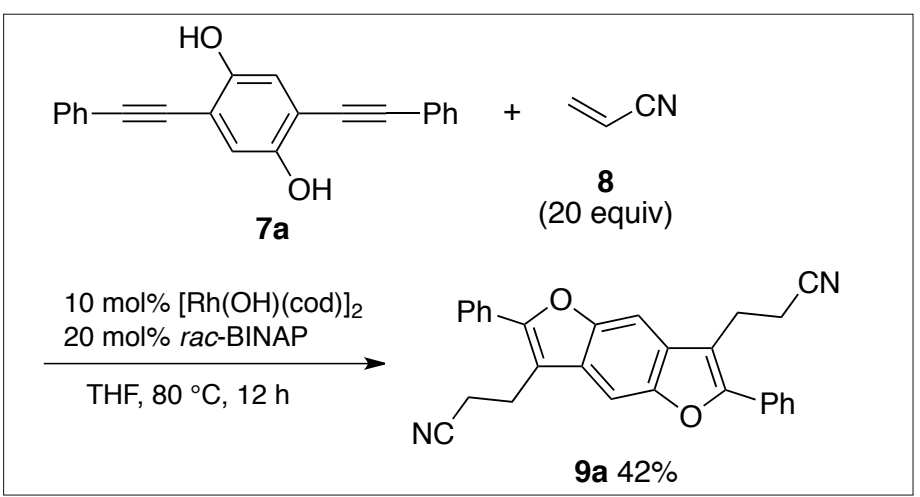

Scheme 6. Reaction of $7 \mathbf{a}$ and 8.

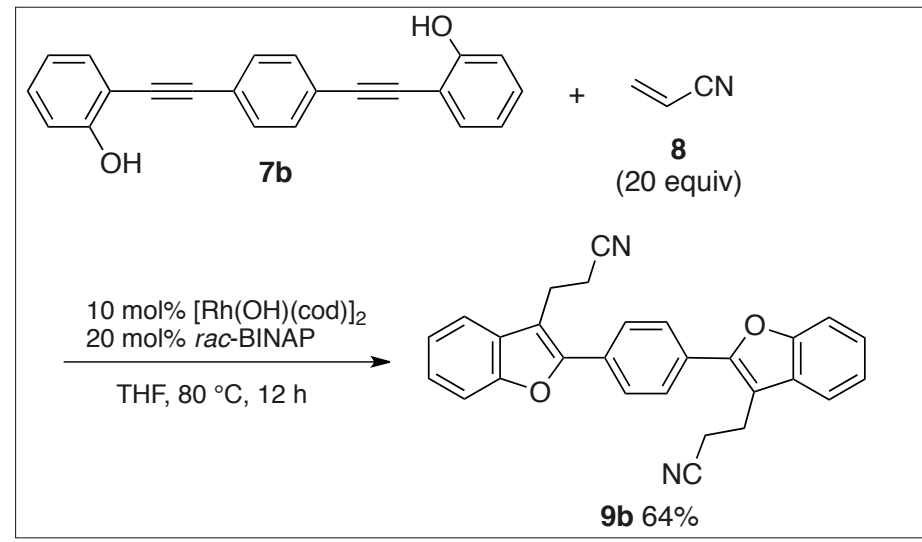

Scheme 7. Reaction of $7 \mathbf{b}$ and 8 .<smiles>C=CC#N</smiles>

Scheme 8. Reaction of $7 c$ and 8. 
noethyl side chains are also synthesized through sequential formation of $\mathrm{C}-\mathrm{O}$ and $\mathrm{C}-\mathrm{C}$ bonds.

\section{Acknowledgements}

This work was supported by JSPS KAKENHI (Nos. 23750115, 25410054, and 16K05783), The Kurata Memorial Hitachi Science and Technology Foundation, and The Sumitomo Foundation.

Received: October 4, 2018

[1] For recent reviews, see: a) J. Wu, in 'FiveMembered Heterocycles: Benzofuran and Related Systems', in 'Modern Heterocyclic Chemistry', Eds. J. Alvarez-Builla, J. J. Vaquero, J. Barluenga, Wiley-VCH, Weinheim, 2011, Vol. 1, Chapter 7, p. 593; b) R. Naik, D. S. Harmalkar, X. Xu, K. Jang, K. Lee, Eur. J. Med. Chem. 2015, 90, 379; c) H. Khanam, Shamsuzzaman, Eur. J. Med. Chem. 2015 97, 483; d) R. J. Nevagi, S. N. Dighe, S. N Dighe, Eur. J. Med. Chem. 2015, 97, 561; e) A. Hiremathad, M. R. Patil, K. R. Chethana, K. Chand, M. A. Santos, R. S. Keri, RSC Adv 2015, 5, 96809; f) M. M. Heravi, V. Zadsirjan, Curr. Org. Synth. 2016, 13, 780; g) M. M Heravi, V. Zadsirjan, H. Hamidi, P. H. T. Amiri, RSC Adv. 2017, 7, 24470.

[2] a) S. Anderson, P. N. Taylor, G. L. B. Verschoor, Chem. Eur. J. 2004, 10, 518; b) J. R. Hwu, K.-S. Chuang, S. H. Chuang, S.-C. Tsay, Org. Lett. 2005, 7, 1545; c) P. A. Vecchi, A. B Padmaperuma, H. Qiao, L. S. Sapochak, P. E. Burrows, Org. Lett. 2006, 8, 4211; d) H. Tsuji, C. Mitsui, L. Ilies, Y. Sato, E. Nakamura, J. Am Chem. Soc. 2007, 129, 11902; e) L. Huo, Y Huang, B. Fan, X. Guo, Y. Jing, M. Zhang, Y. Li, J. Hou, Chem. Commun. 2012, 48, 3318; f) C. Mitsui, J. Soeda, K. Miwa, H. Tsuji, J. Takeya, E. Nakamura, J. Am. Chem. Soc. 2012, 134 5448; g) M. J. Bosiak, J. A. Jakubowska, K. B Aleksandrzak, S. Kamiński, A. KaczmarekKędziera, M. Ziegler-Borowska, D. Kędziera, J Adams, Tetrahedron Lett. 2012, 53, 3923; h) H. Tsuji, E. Nakamura, Acc. Chem. Res. 2017, 50, 396.

[3] a) H. Yamanaka, Y. Kondo, T. Sakamoto, Heterocycles 1989, 29, 1013; b) A. Arcadi, S. Cacchi, M. Del Rosario, G. Fabrizi, F Marinelli, J. Org. Chem. 1996, 61, 9280; c) N. Monteiro, A. Arnold, G. Balme, Synlett 1998 1111; d) Y. Hu, K. J. Nawoschik, Y. Liao, J. Ma, R. Fathi, Z. Yang, J. Org. Chem. 2004, 69, 2235; e) M. Yoshida, Y. Morishita, M. Fujita, M. Ihara, Tetrahedron 2005, 61, 4381; f) Fürstner, A.; Davies, P. W. J. Am. Chem. Soc. 2005, 127, 15024; g) X. Li, A. R. Chianese, T. Vogel, R. H. Crabtree, Org. Lett. 2005, 7, 5437; h) M.
Nakamura, L. Ilies, S. Otsubo, E. Nakamura, Org. Lett. 2006, 8, 2803; i) Y. Liang, S. Tang, X.D. Zhang, L.-Q. Mao, Y.-X. Xie, J.-H. Li, Org. Lett. 2006, 8, 3017; j) B. M. Trost, A. McClory, Angew. Chem., Int. Ed. 2007, 46, 2074; k) Z. Liang, S. Ma, J. Yu, R. Xu, Tetrahedron 2007, 63, 12877; 1) A. Varela-Fernandez, C. GonzálezRodríguez, J. A. Varela, L. Castedo, C. Saá, Org. Lett. 2009, 11, 5350; m) R. N. Nair, P. J. Lee, A. L. Rheingold, D. B. Grotjahn, Chem. Eur. J. 2010, 16, 7992; n) R. Álvarez, C. Martínez, Y. Madich, J. G. Denis, J. M. Aurrecoechea, A. R. de Lera, Chem. Eur. J. 2010, 16, 12746; o) K. Hirano, T. Satoh, M. Miura, Org. Lett. 2011, 13, 2395; p) M. Furusawa, T. Imahori, K. Igawa, K. Tomooka, R. Irie, Chem. Lett. 2013, 42, 1134.

[4] a) N. Isono, M. Lautens, Org. Lett. 2009, 11, 1329 ; b) A. Boyer, N. Isono, S. Lackner, M. Lautens, Tetrahedron 2010, 66, 6468.

[5] For reviews, see: a) K. Fagnou, M. Lautens, Chem. Rev. 2003, 103, 169; b) T. Hayashi, K. Yamasaki, Chem. Rev. 2003, 103, 2829; c) T. Miura, M. Murakami, Chem. Commun. 2007, 217; d) S. Darses, J.-P. Genet, Chem. Rev. 2008, 108, 288; e) S. W. Youn, Eur. J. Org. Chem. 2009, 2597; f) J. D. Hargrave, J. C. Allen, C. G. Frost, Chem. Asian J. 2010, 5, 386; g) H. J. Edwards, J. D. Hargrave, S. D. Penrose, C. G. Frost, Chem. Soc. Rev. 2010, 39, 2093; h) P. Tian, H.-Q. Dong, G.-Q. Lin, ACS Catal. 2012, 2,95 .

[6] The following mechanistic pathway is also conceivable for generation of the (benzofuran-3-yl)rhodium(I) species from 1a. The hydroxorhodium(I) complex activates the carbon-carbon triple bond to induce 5-endo cyclization of the phenolic hydroxy group. Deprotonation from the arising oxonium cation generates the (benzofuran-3-yl)rhodium(I) species.

[7] Intramolecular cyclization in a 5-exo mode would be much easier to occur than intermolecular addition of an organorhodium(I) species to a ketonic carbonyl group. For examples of addition of organorhodium(I) species to a ketonic carbonyl group, see: a) A. Takezawa, K. Yamaguchi, T. Ohmura, Y. Yamamoto, N. Miyaura, Synlett 2002, 1733; b) T. Matsuda, M. Makino, M. Murakami, Org. Lett. 2004, 6, 1257; c) R. Shintani, K. Okamoto, Y. Otomaru, K. Ueyama, T. Hayashi, J. Am. Chem. Soc. 2005, 127, 54; d) S. L. X. Martina, R. B. C. Jagt, J. G. de Vries, B. L. Feringa, A. J. Minnaard, Chem. Commun. 2006, 4093; e) K. Ueura, S. Miyamura, T. Satoh, M. Miura, J. Organomet. Chem. 2006, 691, 2821; f) T. Miura, M. Shimada, M. Murakami, Tetrahedron 2007, 63, 6131; g) J. R. White, G. J. Price, P. K. Plucinski, C. G. Frost, Tetrahedron Lett. 2009, 50, 7365; h) G. M. Gallego, R. Sarpong, Chem. Sci. 2012, 3, 1338; i) Y.-X. Liao, C.-H. Xing, Q.-S. Hu, Org. Lett. 2012, 14, 1544; j) D. W. Low, G. Pattison,
M. D. Wieczysty, G. H. Churchill, Org. Lett. 2012, 14, 2548; k) T. Johnson, K.-L. Choo, M. Lautens, Chem. Eur. J. 2014, 20, 14194; 1) Y. Li, M.-H. Xu, Org. Lett. 2014, 16, 2712; m) L. Huang, J. Zhu, G. Jiao, Z. Wang, X. Yu, W.-P. Deng, W. Tang, Angew. Chem., Int. Ed. 2016, 55, 4527; n) L. S. Dobson, G. Pattison, Chem. Commun. 2016, 52, 11116.

[8] When the acetyl group of 1a was replaced by a formyl group, its decarbonylation preceded the second cyclization to afford 2-phenylbenzofuran in $72 \%$ yield. For recent reviews on decarbonylation of aldehydes, see: a) T. Patra, S. Manna, D. Maiti, Angew. Chem., Int. Ed. 2011, 50, 12140; b) A. Modak, D. Maiti, Org. Biomol. Chem. 2016, 14, 21.

[9] A hydration reaction of the alkyne moiety com peted to lower the low yield of $\mathbf{2} \mathbf{b}-\mathbf{d}$.

[10] For reviews on indole synthesis, see: a) R. Vicente, Org. Biomol. Chem. 2011, 9, 6469; b) S. Cacchi, G. Fabrizi, Chem. Rev. 2011, 111, PR215; c) D. F. Taber, P. K. Tirunahari, Tetrahedron 2011, 67, 7195; d) M. Inman, C. J. Moody, Chem. Sci. 2013, 4, 29; e) N. Yoshikai, Y. Wei, Asian J. Org. Chem. 2013, 2, 466; e) G. Abbiati, F. Marinelli, E. Rossi, A. Arcadi, Isr. J. Chem. 2013, 53, 856; f) I. Kumar, R. Kumar, U. Sharma, Synthesis 2018, 50, 2655.

[11] For recent cascade $\mathrm{C}-\mathrm{N}$ and $\mathrm{C}-\mathrm{C}$ bond forming reactions of 2-alkynylanilines, see: a) $\mathrm{R}$. Shen, T. Kusakabe, K. Takahashi, K. Kato, Org. Biomol. Chem. 2014, 12, 4602; b) Z. Hu, S. Luo, Q. Zhu, Adv. Synth. Catal. 2015, 357, 1060. c) V. Reddy, R. V. Anand, Org. Lett. 2015, 17, 3390; d) A. Gimeno, A. RodríguezGimeno, A. B. Cuenca, C. Ramírez de Arellano, M. Medio-Simón, G. Asensio, Chem. Commun. 2015, 51, 12384; e) A. Mizukami, Y. Ise, T. Kimachi, K. Inamoto, Org. Lett. 2016, 18, 748; f) R. Karmakar, A. Suneja, V. K. Singh, Org. Lett. 2016, 18, 2636; g) S. Guo, K. Yuan, M. Gu, A. Lin, H. Yao, Org. Lett. 2016, 18, 5236; h) C. Qu, S. Zhang, H. Du, C. Zhu, Chem. Commun. 2016, 52, 14400; i) J. Li, C. Li, L. Ouyang, C. Li, W. Wu, H. Jiang, Org. Biomol. Chem. 2017, 15, 7898; j) A. Dagar, S. Guin, S. Samanta Asian J. Org. Chem. 2018, 7, 123.

[12] The product was obtained as a mixture of indistinguishable diastereomers

[13] For studies on the synthesis of benzofuran oligomers, see: a) M. Nakamura, L. Ilies, S. Otsubo, E. Nakamura, Angew. Chem., Int. Ed. 2006, 45, 944; b) A. Kumar, M. Dixit, S. P. Singh, R. Raghunandan, P. R. Maulik, A. Goel, Tetrahedron Lett. 2009, 50, 4335; c) S. Mehta, R. C. Larock, J. Org. Chem. 2010, 75 , 1652; d) J.-M. Suk, K.-S. Jeong, Bull. Korean Chem. Soc. 2010, 31, 561; e) T. Wang, Z.-Y. Li, A.-L. Xie, X.-J. Yao, X.-P. Cao, D. Kuck, J. Org. Chem. 2011, 76, 3231; f) W.-Y. Chai, E.-Q. Yang, Y.-L. Zhang, A.-L. Xie, X.-P. Cao, Synthesis 2012, 44, 439. See also ref. [2a]. 